\title{
Anaesthesia in Wilson's Disease for Laparoscopic Surgery
}

\author{
Agrawal Preeti ${ }^{1 *}$, Kataria Vijayshree ${ }^{2}$, S. Jamuna ${ }^{3}$
}

${ }^{1}$ MD, Anaesthesia, Head of Anaesthesia (ESIC Sahibabad), Ex Sr Maulana Azad Medical College, New Delhi, India

${ }^{2} \mathrm{MD}$, Anaesthesia, Specialist Anaesthesia (ESIC Noida)

${ }^{3} \mathrm{MD}$ Anaesthesia, Senior Resident, ESIC Sahibabad

DOI: $10.36347 /$ sjmcr.2020.v08i04.016

| Received: 10.04 .2020 | Accepted: 17.04.2020 | Published: 22.04.2020

*Corresponding author: Preeti Agrawal

Abstract

Wilson disease is an inherited disorder of altered copper metabolism with accumulation of copper in liver, brain, eyes. Patient may present with cirrhosis, acute liver failure, neuropschychiatric manifestation like tremors, dysarthria, acute psychosis. Anaesthesia in Wilson disease can be a challenging task in laparoscopic surgery, thorough workup of severity, optimal planning is essential hence we discuss a case of 12 year old female child, diagnosed as Wilson disease posted for laparoscopic cholecystectomy. This is first case report of laparoscopic surgery in Wilson disease in our knowledge.

Keywords: Wilson disease, Laparoscopic surgery, Paediatric, cirrhosis.

Key messages: General anaesthesia can be safely administered in paediatric Wilson's disease Patient for laparoscopic surgery with safe and selective usage of drugs and meticulous monitoring of intraoperative and postoperative period. Copyright @ 2020: This is an open-access article distributed under the terms of the Creative Commons Attribution license which permits unrestricted use, distribution, and reproduction in any medium for non-commercial use (NonCommercial, or CC-BY-NC) provided the original author and source are credited.

\section{INTRODUCTION}

Wilson disease (WD) is an autosomal recessive disorder characterized by a reduction in the synthesis of the copper transporter protein ceruloplasmin [1]. WD involves loss of the ability to export copper from the liver into bile and to incorporate copper into ceruloplasmin [2]. There is accumulation of copper in various organs especially in the liver, brain, kidneys, and cornea. Clinical presentations include liver disease, progressive neurological disorder and psychiatric illness. The type of the liver disease can be asymptomatic to acute liver failure or chronic liver disease leading to cirrhosis. Due to existing liver disease, anaesthetic management presents a challenge in WD cases in laparoscopic surgery in terms of anaesthetic technique and anaesthetic drugs to be used.

\section{CASE History}

A 12 year old female diagnosed case of Wilson disease posted for laparoscopic cholecystectomy. In January 2014, patient presented with severe jaundice and haematemesis. Then she was diagnosed as Wilson disease with portal hypertension with splenomegaly. At that time, Serum Ceruloplasmin was $.019 \mathrm{mg} / \mathrm{dl}(.2-.6$ $\mathrm{mg} / \mathrm{dl}), 24$ hour urinary copper was $163.3 \mu \mathrm{g} /$ day $(20$ $50 \mu \mathrm{g} /$ day), serum copper $20.10 \mu \mathrm{g} / \mathrm{dl}(\mathrm{70}-140 \mu \mathrm{g} / \mathrm{dl}), 2$ Heterozygous ATP 7B mutations +, Fibro scan 29 $\mathrm{kPa}$ (normal 2-6 kPa), Kayser-Fleischer rings (KF rings) were positive. Liver biopsy showed cirrhotic changes. She was started on Tab D-penicillamine $250 \mathrm{mg} \mathrm{BD}$, Tab Zinconia BD.

At present patient weight was $35 \mathrm{Kg}$. Pulse rate of $90 / \mathrm{min}, \mathrm{BP}-100 / 70$ with adequate mouth opening, mallampati grading was II. Her haemoglobin was $10.5 \mathrm{~g} / \mathrm{dl}$, platelet $1.6 \mathrm{~L} / \mathrm{mm}^{3}$, serum bilirubin .96 $\mathrm{mg} / \mathrm{dl}$, aspartate amino transferase $56 \mathrm{U} / \mathrm{L}$, alanine aminotransferase $60 \mathrm{U} / \mathrm{L}$, total protein $7.3 \mathrm{~g} / \mathrm{dl}$, albumin $4 \mathrm{~g} / \mathrm{dl}$, International normalised ratio 1.09, fibro scan decreased to 9.8 , Thyroid stimulating hormone 2.25 $\mathrm{mU} / \mathrm{L}$. All other investigations were normal.

As patient was on regular medical treatment with normal investigations, we proceeded for laparoscopic surgery. Preoperative order was given to continue drugs till 12 hours before surgery. Patient was taken with adequate nil per oral status. Informed written consent taken from parents. Fasting blood sugar was 90 $\mathrm{mg} / \mathrm{dl}$.

General anesthesia was induced with intravenous $70 \mathrm{mg}$ propofol, $70 \mu \mathrm{g}$ fentanyl, $20 \mathrm{mg}$ atracurium, and maintained with $0.8-1.5 \%$ isoflurane in $50 \%$ air and $50 \%$ oxygen. $\mathrm{ETCO}_{2}$ was maintained between $28-34 \mathrm{~mm} \mathrm{Hg}$. Intraabdominal pressure was raised slowly and kept less than $12 \mathrm{~mm} \mathrm{Hg}$. Ringer lactate $500 \mathrm{ml}$ intravenously given during surgery. 
Patient was haemodynamically stable throughout the surgery and urine output was also adequate. Injection paracetamol $500 \mathrm{mg}$ intravenously given for postoperative analgesia. Injection neostigmine $2 \mathrm{mg}$ and glycopyrrolate $0.4 \mathrm{mg}$ intravenously given on completion of surgery. Patient was extubated awake and taken to the intensive care unit for further monitoring. There was no postoperative deterioration in the liver or renal functions. Zinc sulphate and D-penicillamine restarted 12 hours after surgery.

\section{DisCUSSION}

Wilson's disease (WD) is an autosomal recessive disorder with an estimated incidence of 1 : 40,000 characterized by hepatic, ophthalmic, and neuropsychiatric symptoms from excess copper accumulation [3]. WD diagnosed and assessed by serum ceruloplasmin, 24 hour urinary copper excretion, serum copper, KF rings, Fibroscan which is USG assessment of fibrosis in liver. WD is characterized by low ceruloplasmin, high 24 hour urinary copper excretion, low serum copper, increased fibroscan value. Reducing dietary copper intake, antagonizing its absorption with zinc, chelation with penicillamine, trientine or ammonium tetrathiomolybdate are treatment options. Liver transplantation is indicated when all treatment measures failed $[4,5]$.

General, subarachnoid and epidural anesthesia have all been reported in patients with Wilson's disease. Successful general anaesthesia has been described by Baykal et al. in a 4-year-old child with Wilson's disease [6]. Nanjangud et al. reported a case where they have successfully managed abscess drainage in a 15 years old girl with Wilson's disease [7]. Mohanty described successful general anaesthetic management of 21 year old patient posted for lower segment caesarean section [8]. Laparoscopic surgery became a safe and effective procedure in patients with symptomatic cholelithiasis and liver cirrhosis especially Child-Turcotte-Pugh (CTP) A and B after improved laparoscopic surgery, availability of newer instruments (i.e. ultrasonic shears) and better perioperative care $[9,10]$.

In view of nature of surgery, we proceeded with general anaesthesia. Aim of anaesthesia management was to maintain stable haemodyamics to avoid decrease in hepatic blood flow, to use drugs which are least metabolized by liver and not affecting liver function. Intraabdominal pressure should be raised slowly and should be kept below $12 \mathrm{mmHg}$ in older children, this pressure causes minimal effect on cardiac index $[11,12]$. In our case, we used propofol, fentanyl and atracurium. Hepatic extraction of propofol exceeded hepatic blood flow so clearance is not significantly altered by liver disease although there is increased sensitivity to sedative and cardio respiratory depressant effects of propofol so it should be given slowly with adequate preloading. Due to elevated copper level and use of penicillamine which interfere with neuromuscular transmission, sensitivity to muscle relaxants increased. We have used atracurium, which is considered safe in liver disease due to its spontaneous degradation by Hoffmann elimination. Fentanyl, a narcotic which is least affected by liver disease and isoflurane which increases hepatic regional blood flow by maintaining hepatic arterial buffer response [13].

The pharmacokinetic parameters of paracetamol are altered in patients with severe liver disease [14]. In our case, because of normal liver enzymes, we have used paracetamol for post operative analgesia. Diclofenac in liver disease can precipitate renal impairment via constriction of afferent glomerular arterioles and hence reduced renal perfusion, so we avoided use of diclofenac [15]. Medical therapy should be restarted as soon as possible postoperatively as break in pharmacologic therapy result in copper accumulation.

In conclusion, general anesthesia for laparoscopic surgery can be successfully administered in a paediatric case of Wilson disease using agents whose pharmacodynamic and pharmacokinetic least affected by liver.

\section{REFERENCES}

1. De Souza Hobaika AB. Anesthesia for a patient with Wilson's disease--a case report. Middle East Journal Anesthesiol. 2008;19(4):905-908.

2. Markiewicz-Kijewska M, Szymczak M, Ismail H, Prokurat S, Teisseyre J, Socha P, Jankowska I, Chyzyńska A, Kaliciński P, Migdał M. Liver transplantation for fulminant Wilson's disease in children. Annals of transplantation. 2008;13(2):2831.

3. Roberts EA, Schilsky ML. Diagnosis and treatment of Wilson disease: an update. Hepatology. 2008;47(6):2089-2111.

4. Ala A, Walker AP, Ashkan K, Dooley JS, Schilsky ML. Wilson's disease. He Lancet, 2007;369: 397-408.

5. Brewer GJ. Recognition, diagnosis, and management of Wilson's disease. Proc Soc Exp Biol Med, 2000;223:39-468.

6. Baykal M, Karapolat S. Anesthetic management of a pediatric patient with Wilsons disease. Journal Clin Med Res, 2010;2:99-101.

7. Nanjangud PR, Prasad S. Anaesthetic management in Wilson's disease with severe neuropsychiatric manifestations. Sri Lan Journal of Anaesthesiol, 2017;25:110-112.

8. Mohanty B. Anaesthetic Management in a Case of Wilson's Disease in Pregnancy. Journal Anesth Clin Res, 2018;9:845.

9. Schiff J, Misra M, Rendon G, Rothschild J, Schwaitzberg S. Laparoscopic cholecystectomy in cirrhotic patients. Surg Endosc. 2005;19:12781281 . 
10. El-Awadi S, El-Nakeeb A, Youssef T, Fikry A, Abd El-Hamed TM, Ghazy H. Laparoscopic versus open cholecystectomy in cirrhotic patients: a prospective randomized study. International Journal Surgery, 2009;7:66-69.

11. Sunita G. Anaesthesia for pediatric laparoscopy, Anestesia Pediatrica e Neonatale, 2006:4(1). http:// www.anestesiarianimazione.com/2006/01d.asp.

12. Pennant JH. Anesthesia for laparoscopy in the pediatric patient. Anesthesiol Clin North Am, 2001;19:69-88.
13. Maze M, Bass NM. Anaesthesia and the hepatobiliary system In: Miller RD, Millers Anaesthesia (5th edn) Churchill Livingstone, Philadelphia. 2000.

14. Bosilkovska M, Walder B, Besson M, Daali Y, Desmeules J. Analgesics in patients with hepatic impairment: pharmacology and clinical implications. Drugs, 2012; 72:1645-1669.

15. Dwyer JP, Jayasekera C, Nicoll A. Analgesia for the cirrhotic patient: A literature review and recommendations. Journal Gastroenterol Hepatol, 2014;29:1356-1360. 